\title{
A social identity perspective on interoperability in the emergency services: Emergency responders' experiences of multi-agency working during the COVID-19 response in the UK
}

Louise Davidson ${ }^{1}$, Holly Carter ${ }^{2}$, Richard Amlot ${ }^{2}$, John Drury ${ }^{1}$, Alex Haslam ${ }^{3}$, Matthew Radburn ${ }^{4}$, Clifford Stott ${ }^{4}$

1 University of Sussex

2 Public Health Englan

3 University of Queensland

4 Keele University

Funding: John Drury, Holly Carter, Matthew Radburn and Clifford Stott were supported by a grant from UKRI, reference ES/V005383/1. Holly Carter and Richard Amlôt are funded by the National Institute for Health Research Health Protection Research Unit (NIHR HPRU) in Emergency Preparedness and Response (EPR) at King's College London in partnership with Public Health England (PHE), in collaboration with the University of East Anglia and Newcastle University and the NIHR HPRU in Behavioural Science and Evaluation in partnership with the University of Bristol. Louise Davidson is also affiliated to the EPR HPRU and her PhD research is jointly funded by the Fire Service Research and Training Trust and the University of Sussex. The views expressed are those of the author(s) and not necessarily those of the NHS, the NIHR, the Department of Health and Social Care or the UK Health Security Agency. The authors have no conflicts of interest to declare.

Potential competing interests: The author(s) declared that no potential competing interests exist.

\section{Abstract}

Recent research has shown that multi-agency emergency response is beset by a range of problems, calling for a greater understanding of the way in which these teams work together to improve future multi-agency working. Social psychological research shows that a shared identity within a group can improve the way in which that group works together and can facilitate effective outcomes. In the present study, 52 semi-structured interviews were conducted with 17 strategic and tactical responders during the COVID-19 pandemic to understand the possible role of shared identity in the multi-agency response to COVID-19. Findings suggest that two forms of group relations were particularly relevant: horizontal intergroup relations - the relationships among responders at the local level; and vertical intergroup relations - the relationship between responders at the local level and national level. Three key factors appeared to contribute to an effective multi-agency response. First, pre-existing relationships with other responders facilitated the ease with which responders were able to work together initially. Second, a sense of 'common fate' helped bring responders together, and finally, Chairs of groups were able to strategically reinforce a sense of shared identity within the group.

\section{INTRODUCTION}

In the UK, a major incident is defined as any event or situation which requires the implementation of special arrangements by one or more emergency responder agencies (Cabinet Office, 2013a). Major incidents can have devastating effects on both human welfare and society, as demonstrated in recent examples from the UK - for example, the Manchester Arena attack and the Grenfell Tower fire (both 2017), the Salisbury nerve-agent attack (2018) and the COVID-19 pandemic (2020-present).

Despite the experience the UK has in planning a multi-agency response, interoperability between responding agencies - in other words the way which they work together to tackle major incidents (Joint Emergency Services Principles [JESIP], 2013) - has been consistently highlighted as a key challenge that hinders effective response. Indeed, in a review of 32 major incidents between 1986 to 2010, coordination between responding agencies was identified as a persistent problem (Pollock, 2013). To address this, JESIP was introduced in 2012 to provide principles for joint working - these are set out in Table 1.

Table 1. The five principles for joint working (JESIP, 2013)

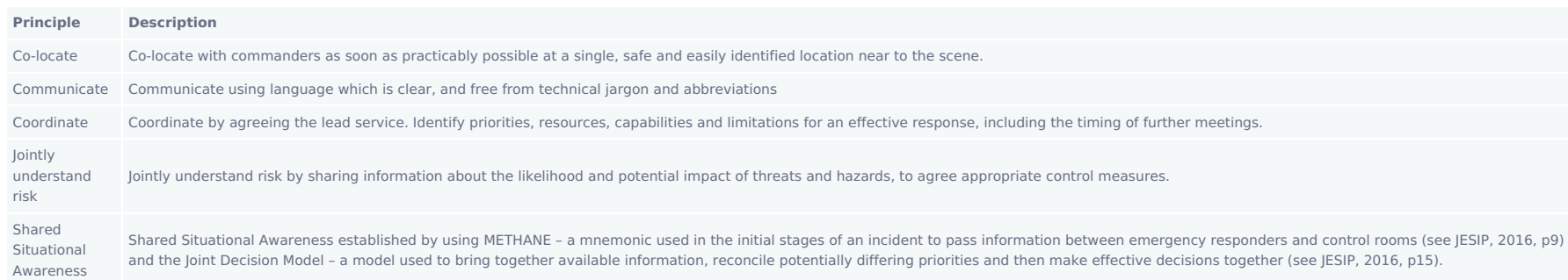

However, interoperability has continued to be highlighted as a problematic issue in emergency response. For example, the Manchester Arena attack enquiry observed that communication failures between the emergency services led to significant delays in the Fire and Rescue Service (FRS) arriving at the scene (Britton, 2021; cf. Kerslake 2018) This suggests that lessons identified in previous reports are not being learned (cf. Pollock, 2017; 2021) and highlights the need for better understanding of why interoperability challenges persist.

Interoperability has also been foregrounded by the COVID-19 pandemic. The pandemic has required a multi-agency response both at the vertical level, involving interactions between groups at the local and national level (e.g. between local multi-agency groups and government agencies), but also at the horizontal level, involving interactions between groups at the local level. Here, sub-groups (e.g. different emergency service organizations) have needed to work together to tackle challenges. Accordingly, in 2020 multi-agency coordination groups were established across the UK to bring together local responders from organizations including the emergency services, local authorities, and other key organizations to provide a joined-up response to COVID-19.

In the present research we zero in on the multi-agency response to COVID-19 in order to try to better understand the factors that might facilitate or challenge an effective multi-agency response. For this purpose, we carried out a series of semi-structured interviews with Police, FRS, and Ambulance responders from across the UK who were 
involved in the COVID-19 response at a strategic or tactical level. Specifically, we sought to address a gap in current research by exploring the role of shared identity in multiagency working in this context: was this relevant, how did it arise, how did it function? However, before describing this research, we first provide an overview of the emergency response context in the UK, a summary of research into interoperability, and introduce the Social Identity Approach.

\subsection{The Emergency Response Context}

Within the UK, the multi-agency response to major incidents is managed through a three-tiered structure set out in the Civil Contingencies Act (CCA) 2004 (see Table 2). This structure brings together partners from Category 1 (e.g., the emergency services, local authorities, the NHS) and Category 2 responding agencies (e.g. the Highway Agency and public utility companies; Cabinet Office, 2013b).

Table 2. Tiers of command and associated responsibilities emergency responders adopt when responding to incidents (JESIP, 2016).

\begin{tabular}{ll}
$\begin{array}{l}\text { Tiers of } \\
\text { command }\end{array}$ & Associated responsibilities \\
\hline Strategic & $\begin{array}{l}\text { Sets strategic direction } \\
\text { Co-ordinated responders } \\
\text { Prioritises resources }\end{array}$ \\
\hline Tactical & $\begin{array}{l}\text { Interprets strategic direction } \\
\text { Develops tactical plan } \\
\text { Co-ordinates activities and assets }\end{array}$ \\
Operational & $\begin{array}{l}\text { Executes tactical plan } \\
\text { Commands single-service response } \\
\text { Coordinates actions }\end{array}$ \\
\hline
\end{tabular}

Multi-agency coordinating groups are often established at the strategic (Strategic Coordinating Group; SCG) and tactical (Tactical Coordinating Group, TCG) levels in a multiagency response (Cabinet Office, 2013b). Here representatives from relevant agencies come together to provide a vital coordination role in an incident response (CCA, 2004). Accordingly, it is important to ensure the factors impacting effective multi-agency working at a strategic and tactical level are properly understood.

\subsection{Understanding Interoperability}

Previous research looking at the strategic and tactical levels of emergency response has been focussed on factors such as decision-making (e.g. Power \& Alison, 2017; Waring et al., 2020; Wilkinson et al., 2019; 2021) and information sharing (e.g. Waring et al., 2018). Amongst other things, one thing that this research shows is that the composition of the group can be an important determinant of effective group decision-making (see Bang \& Frith, 2017, for a review). This supports the idea that group composition is an important element of emergency response and reinforces the need to further understand group working in these contexts.

To understand the experiences of local and national strategic decision makers in the COVID-19 response, three reviews were conducted in 2020, and multi-agency working was identified as a prevalent theme (Hill et al., 2020a, 2020b, 2020c). Factors facilitating effective multi-agency working included pre-existing relationships between responders and effective leadership. On the other hand, factors that challenged multi-agency working included responders having no prior knowledge of structures and procedures, and a lack of information sharing from a national to local level.

Whilst previous research has sought to better understand interoperability in multi-agency response (e.g. Wilkinson et al., 2021), further research is required to better understand psychological group processes in these unique contexts. More specifically, in order to make interoperable working as effective as possible, we first need to understand how individuals from separate organisations come to work together interdependently as a group. To our knowledge, research has not yet explored how social identity principles might impact interoperability. Below we introduce the Social Identity Approach and discuss how shared identity and organizational behaviour might help understand multi-agency working better.

\subsection{Shared identity and organizational behaviour}

The Social Identity Approach is a social psychological framework that seeks to understand the distinct contribution that group life makes to people's psychology and behaviour. The approach is comprised of two inter-related theories - social identity theory (Tajfel \& Turner, 1979) and self-categorization theory (Turner et al., 1987) - that are built upon a foundational insight that as well as defining themselves, and behaving, in terms of their personal identity as individuals (Turner, 1982), people can, and often do, also define themselves, and behave, in terms of their social identity as members of social groups (Tajfel \& Turner, 1979). So, whereas personal identity defines a sense of ' $I$ ' and 'me' that describes a person in contrast to others, social identity defines the self in terms of 'we' and 'us' in ways that psychologically connect people to other members of their ingroup.

In a range of social and organizational contexts, this sense of social identity is observed to be the primary driver of people's behaviour primarily because, as Turner (1982, p.21) argues, it is what "makes group behaviour possible" (cf. Haslam et al., 2003). In particular, a shared identity within a group is a basis for coordination and cooperation between group members because it increases their psychological sense of inter-connection and common purpose (Haslam et al., 2009; 2021). At the same time, it can provide group members with shared definitions of situations, as well as common norms for behaving in those situations (Reicher et al., 2010). Consequently, these shared definitions and common norms can increase the ability of those who perceive themselves to share social identity (i.e., who are bound by a common sense of 'us') to work effectively together (Drury et al., 2009; Haslam et al., 2009) while also fostering trust and respect among group members (Haslam et al., 2012; Turner et al., 1987).

Demonstrating these positive effects, Haslam et al. (2009) showed that individuals who had high group identification were more willing to display organization citizenship than those with lower levels of identification. More generally, a large body of research demonstrates that when group members perceive themselves to share social identity, this increases their motivation to contribute to the groups' success, as well as their ability to do so (as reviewed by Ellemers et al., 2004; Haslam, 2004). 
At the same time though, people also have multiple social identities which can each become salient in different contexts (e.g., us women, us Londoners, us paramedics; Millward \& Haslam, 2013; Turner et al., 1987). According to self-categorization theory, these can also be defined at multiple levels of abstraction (Turner, 1985). For example, a paramedic, Anne, can define herself, as a member of a particular team, as a member of a particular profession, or as an emergency worker. It follows too that this is likely to have a significant bearing on her behaviour. For example, when (and to the extent that) she defines herself as a member of a particular team Anne should be motivated to advance the interests of that team but when (and to the extent that) she defines herself as an emergency service worker Anne should be motivated to advance the interests

of emergency service workers.

This analysis is clearly relevant to interoperability in multi-agency response because the organizational entities here (e.g., SCG and TCG's) typically involve individuals from usually independent organizations who are required to work collectively and collaboratively with each other. In particular, responders are required to jointly provide the overall multi-agency management of the incident, yet they still have agency-specific responsibilities (Cabinet Office, 2013b) which can conflict with the overall superordinate goal of the response (Mathieu et al., 2001). As a result, there is a need to understand what factors impact interoperability in a multi-agency response to improve the effectiveness of these unique groups in future incidents. Hitherto, though, despite its obvious relevance, social identity theorising has not been used to gain traction on this issue. This is therefore the goal of the present research.

\subsection{The present study}

Existing research highlights the recurring problems that arise in multi-agency response and calls for a greater understanding of the way in which these teams work together, in order to improve multi-agency working in the future. Potentially exacerbating existing challenges, the COVID-19 pandemic has presented a unique set of challenges to emergency responders, in terms of the scale, longevity and complexity of the response required. For example, most emergencies in the UK are handled at the local level with no direct involvement from a national level (Cabinet Office, 2013b). Here interoperable working requires positive relationships between those at the horizontal (i.e. local) level. However, in the COVID-19 response, central Government played a leading role in the response. This added additional considerations for responders to manage this vertical relationship, as well as their relationships with each other at a horizontal level.

With this in mind, we conducted regular, semi-structured interviews with responders at the strategic and tactical levels of response from across the UK. The purpose of this was to understand the possible role of shared identity in the multi-agency response during the initial months of the pandemic in 2020 . More specifically, the aims of this research were to identify:

1. The key challenges that emergency responders felt they experienced in the multi-agency response to COVID-19 at the strategic and tactical level.

2. Whether there was any evidence that emergency responders' shared identities were bound up with these challenges and/or were part of the solution to them.

3. If so, how and when a shared identity arose in these multi-agency groups.

\section{METHOD}

\subsection{Participants}

Fifty-two semi-structured interviews were conducted with 17 responders from the Police $(N=8)$, Fire and Rescue $(N=7)$ and Ambulance Service $(N=2)$ who were involved in the COVID-19 response at a strategic and/or tactical level - all responders were involved in the SCG and/or TCG within their local area (see Table 3 for a full list of participant details). Repeated Interviews took place between $13^{\text {th }}$ April 2020 and $27^{\text {th }}$ July 2020 . Due to commitments in the ongoing COVID-19 response, responders took part in an unequal number of interviews, ranging between 1 and 12 each $(M=4, S D=3.15)$.

Table 3. Participant information

\begin{tabular}{ll|lll|l} 
Participant & Organisation & SCG/TCG & Region & Gender & $\begin{array}{l}\text { Number of interviews } \\
\text { conducted }\end{array}$ \\
\hline 1 & Fire and Rescue & SCG & Wales & Male & 1 \\
\hline 2 & Fire and Rescue & SCG & London & Male & 12 \\
\hline 3 & Fire and Rescue & SCG & London & Male & 6 \\
\hline 4 & Police & TCG & East & Male & 3 \\
\hline 5 & Police & SCG & Wales & Male & 9 \\
\hline 6 & Police & TCG & West Midlands & Male & 4 \\
\hline 7 & Ambulance & SCG & West Midlands & Male & 2 \\
\hline 8 & Police & SCG & Northern Ireland & Male & 2 \\
\hline 9 & Fire and Rescue & SCG & South East & Male & 1 \\
\hline 10 & Fire and Rescue & SCG & South East & Male & 1 \\
\hline 11 & Fire and Rescue & SCG & South East & Male & 3 \\
\hline 12 & Police & TCG & Wales & Male & 1 \\
\hline 13 & Fire and Rescue & TCG & London & Male & 1 \\
\hline 14 & Police & SCG \& TCG & North West & Male & 2 \\
\hline 15 & Police & TCG & South East & Male & 2 \\
\hline 16 & Police & TCG & South East & Female & 1 \\
\hline 17 & Ambulance & SCG \& TCG & Scotland & Male & 1 \\
\hline
\end{tabular}

Note: Participant's age was not recorded.

\subsection{Procedure}

Interviews took place either over the telephone or via the online platform, Microsoft Teams and were recorded with a dictaphone. Responders were provided with an 
information sheet electronically before their first interview. A consent protocol was read out to responders before their first interview and they were asked to verbally consent to take part.

Subsequent interviews were carried out between 6 and 56 days after the previous interview $M=17$ days, $S D=13.2)$. The first interview for each responder lasted on average 41 minutes ( $\max =\sim 57$ minutes, $\min =\sim 26$ minutes). Subsequent interviews lasted on average 23 minutes (max $=\sim 42$ minutes, min $=\sim 11$ minutes).

\subsection{Interview schedule}

The interview schedule was developed following discussions between members of the research team. For the first interview, questions focussed around roles and responsibilities (e.g. "What is your current role within the COVID-19 response?"), multi-agency working (e.g. "Can you tell me about the range of partners that you are involved with in this response?"); strengths and weaknesses (e.g. "Can you tell me about any challenges you have faced?"); adaptation (e.g. "Are there any specific areas of improvement that you have recognised in this response?"); and training and guidance ("Is there any specific training or guidance you are following in your response?"). Subsequent interviews focussed on any changes or developments in the response since the previous interview. The full interview schedules can be found in the Supplementary Materials $1 \& 2$.

\subsection{Context}

The role of the SCG in the COVID-19 response was to take overall responsibility of the response, and to establish the strategic framework within which the tactical and operational levels of command could operate. On the other hand, the role of the TCG was to provide a co-ordinated tactical response to COVID-19. For example, responders discussed their role included supporting personal protective equipment deliveries, setting up temporary mortuaries, ensuring the vulnerable population are adequately cared for. In addition, in most of the areas interviewed the Police chaired the SCG and/or TCG. In one area the FRS chaired the SCG. When Police or FRS did not chair SCG and/or TCG meetings, these were chaired by the Health sector.

A summary of key dates and events provided by participants during the interviews is presented in Table 4 . A summary of key considerations provided by responders that their SCG and TCG's needed to discuss to facilitate the operational response during this time period is also presented in Table 4.

Table 4. Summary of key dates, events and response considerations

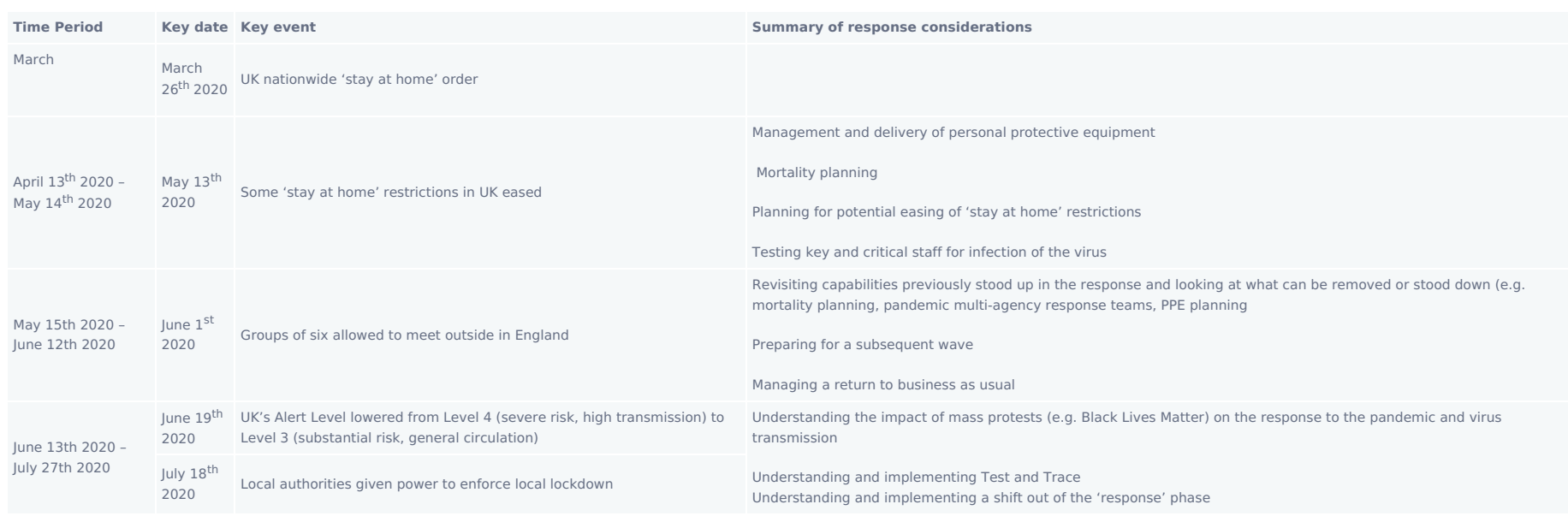

\subsection{Data analysis}

Interviews were analysed using thematic analysis - a method for identifying, analysing and reporting themes (patterns) in data (Braun \& Clarke, 2006). A semi-deductive approach was utilised - whilst there were no pre-determined themes, the Social Identity Approach provided researchers with a general sense of reference when formulating the research questions and conducting the analysis (e.g. use of 'us vs. them' language). Data familiarisation took place by the lead author listening to the recordings of all interviews and then transcribing sections of interviews relevant to the multi-agency response to COVID-19. Sections of the interview where responders discussed other response activities that were not specific to the multi-agency response to COVID-19 (e.g. the Black Lives Matter protests during Summer 2020) were not included. The lead author then read, and re-read transcribed interviews to identify sections of the transcripts which were relevant to the research question - for example, any evidence that social identity principles might be present, or any processes that might be facilitating group working. From this, initial codes were provided for these sections (e.g. communication outside of the local area). These codes were then reviewed and discussed with the research team, and potential themes were identified (e.g. cross-area information sharing). Themes were separated into two key topic areas based on the two intergroup relations most prevalent in this response (horizontal and vertical intergroup relations) to enable the evidence provided to be presented in the most coherent way to answer the research questions. The research team met on a fortnightly basis throughout the analytical process to discuss the analysis.

\section{RESULTS}

The results are presented under two key topic areas: horizontal and vertical intergroup relations (see Table 5).

Table 5. Overview of topic areas and themes. 


\begin{tabular}{|c|c|c|c|c|}
\hline Topic Area & Theme & Definition & $\begin{array}{l}\text { Total number of } \\
\text { interviews (Interview } \\
\text { 1) }\end{array}$ & $\begin{array}{l}\text { Total number of } \\
\text { responders }\end{array}$ \\
\hline \multirow[t]{3}{*}{$\begin{array}{l}\text { Horizontal intergroup relations: the relationship between different } \\
\text { organizations at the same level within a local area }\end{array}$} & $\begin{array}{l}\text { Pre-existing } \\
\text { relationships }\end{array}$ & Relationships in place between responders before the COVID-19 pandemic. & $19(12)$ & 14 \\
\hline & $\begin{array}{l}\text { Understanding roles of } \\
\text { partners }\end{array}$ & $\begin{array}{l}\text { Responders having a clear understanding of what the roles and goals of partners } \\
\text { from different agencies are in the response to COVID-19. }\end{array}$ & $16(10)$ & 12 \\
\hline & $\begin{array}{l}\text { Shared understanding } \\
\text { of the response }\end{array}$ & $\begin{array}{l}\text { Responders from different agencies all having the same awareness and } \\
\text { understanding of the COVID-19 response. }\end{array}$ & $22(8)$ & 12 \\
\hline \multirow[t]{2}{*}{$\begin{array}{l}\text { Vertical intergroup relations: the relationship between responders at } \\
\text { a local level and national government agencies }\end{array}$} & Communication & $\begin{array}{l}\text { Challenges in communication and information sharing between national } \\
\text { government organizations and responders at the local level. }\end{array}$ & $32(12)$ & 13 \\
\hline & $\begin{array}{l}\text { Cross-area lesson } \\
\text { sharing }\end{array}$ & $\begin{array}{l}\text { Local level responders sharing information with regional, national and international } \\
\text { partners. }\end{array}$ & $12(5)$ & 6 \\
\hline
\end{tabular}

The themes are presented alongside representative extracts from the interviews. For anonymity, each responder was given a unique participant number (1-17; see Table 3) which is presented alongside extracts. Non-typical quotes are highlighted in the results.

\subsection{Horizontal intergroup relations}

3.1.1 Pre-existing relationships. In early interviews, nearly all responders said a key strength of the response was how well everyone came together as a group to put a response in place in such uncertain terms, and credited pre-existing relationships between partners from different organizations in facilitating this:

In a long-playing incident like this you can utilise those relationships you have already got and work quite effectively as opposed to coming together at the point the incident started and develop the relationships from there. So, having those pre-existing relationships is what has made this response so effective (P7).

One responder said that they already trusted each other and saw each other as a "unit" (P5). Furthermore, one responder from London described their partnership as "welloiled" due to the regular recent incidents they had attended, such as the London Bridge and Finsbury Park attacks, and Grenfell Tower fire (P3). Another responder from London expanded on this saying they have "worked as one" for so long (P2).

Yet, it is not just about the presence of pre-existing relationships that helped the group come together, some responders suggested the quality of that relationship was also important in group working. For example, knowing people on first name bases and having their phone numbers already saved could help resolve challenges quickly. One responder said that friendly relationships can help "lighten the mood" when the pressure on them is high (P12). In addition, another responder said friendly relationships are beneficial not just for the current response, but also for future group working:

The fundamental foundation of what we have been able to do has been the relationships [...] we work hard for each other because we like each other and trust each other and know each other's issues and we have a trusting relationship whereby we can have open conversations. We have committed to each other to develop these relationships which will put us in good stead in the future [...] I am confident we can resolve an incident because of the relationships that we have (P11).

Some responders commented that the unique nature of COVID-19 which required people to work remotely where possible initially created challenges in getting to know others when pre-existing relationships were not formed due to the lack of face-to-face interaction:

What is harder with COVID-19 than in a usual incident is that if you don't know another responder at all and if they are now ringing into these meetings rather than attending them, due to social distancing, it is much harder to get that relationship (P2).

Yet, responders from the South East discussed setting up a Strategic Coordination Centre (SCC) where they were able to co-locate and have meetings in person. One responder from this area said that being able to physically attend the SCC made it easier to know who people were and who they needed to speak to.

3.1.2 Understanding the roles of partners. Several responders said that the biggest difference of the COVID-19 response compared to other incident responses is that it is a health-led initiative and they have spent a lot of time trying to understand the nature of the health service. Exacerbating this challenge, one responder (P4) said they had a health Chair of the SCG who had not previously chaired an SCG before and it took them a couple of weeks to fully understand the purpose of the group.

In addition, one responder (P12) said that the COVID-19 response involved a number of guest agencies who would not normally be involved in a response, such as the prison and probation service. This created challenges with new partners being initially hesitant to share problems they were facing leading to delays in resolving them. Yet, in later interviews some responders said that this challenge eased as time went by:

That [misunderstanding of roles] was [...] across all partners not fully understanding what others can do. As time went on it became clearer what everyone was bringing to the table (P14).

Further, in an initial interview, one responder (P4) highlighted the important role of the Chair of the group in facilitating an understanding of roles amongst partners through going over the roles and responsibilities of each partner at the beginning of the response. Later on, another responder said that once they had overcome initial differences between partners, they were able to collectively deal with any challenges, rather than working independently of each other:

[We] now can have those open conversations between services to address issues as they arise and face challenges as a team as opposed to individual organisations in 
their own silos. Rather than coming up with individual solutions, what we have come up with now is a combined solution that everyone is comfortable with (P6).

3.1.3 Shared understanding of the response. Initially, some responders said the shared threat of COVID-19 brought them together and facilitated their group working One responder said the threat of COVID-19 allowed partners to work collectively in the response because they had a "unity", "one aim" and were all "working to the same goal" (P5). Other responders said they were all working together for "a common purpose" (P6) and convening around "a common enemy" (P11).

However, in later interviews some responders said that different organizations developed a different understanding of where they were at in the response, and that this reduced the shared sense of common fate. One responder who initially talked about the unity of the group said that later in the response the group cohesiveness that was originally formed started to weaken because there was no longer a clear common purpose for why they were convening:

It takes an external threat for everyone to come together to work for the greater good and taking one for the team [...] but as soon as that external threat slightly dissipates, even if it is just that we are over the initial peak [...] everyone starts petty squabbling and it just unravels from the top (P5).

To try to overcome this challenge and maintain group cohesiveness, this responder said they laid out eight strategic goals for the SCG at the beginning of each meeting. Further, another responder said that they began each of their SCG meetings with an overview of the common picture of the incident, so that each partner knew exactly what was happening, what the challenges were, and what actions needed to be taken:

At the start of the meeting you start with this is where we are and these are the previously identified risks [...] everyone needs to leave the room with a clear line of sight of everyone else's position [...] no matter where they are from, they have a clear line of sight of what is happening [...] where the pinch points are and what mitigating action needs to be taken (P12).

In response to the changing situation, one responder said that their SCG introduced a new phase called 'stabilisation' which occurred after the initial response phase, but before the recovery phase. Within this phase, the SCG members were not meeting regularly as they had done in the initial response phase, but partners were still working together and ready to meet again if or when it was necessary. This was so that partners were aware they still had access to the resources and support the SCG could provide:

The other alternative is to close [the SCG] down and the message that sends is message complete [their response to COVID-19 is over] [...] that sends all kinds of dangerous signals so the other alternative is to leave it running in the background so it is technically in existence but there is nothing happening in it [...] the SCG is a leadership group of senior people across the partnership saying this is still very important to us. If we all walk away [...] what we're saying is it's not very important anymore (P11).

\subsection{Vertical intergroup relations}

3.2.1 Communication. Throughout, a key challenge consistently highlighted by nearly all responders centred on communication between national and local level. In particular, responders reported that challenges were created by receiving key announcements from central Government at the same time as the public. One responder said that not having a clear idea of changes in policies made it very difficult to prepare and to provide a timely response:

With other incidents it is much more clear about what is going to happen next, the big thing with this one is [...] we are finding out at the same time as everyone else, then having to respond to this as a strategic and tactical body, which is unusual in responses to emergencies because usually we know what is coming next and can start to plan and map out what it looks like. Finding out at the same time as everyone else makes it a little more interesting (P4).

This communication challenge seemed to be exacerbated in the devolved nations of Northern Ireland and Wales. A responder from Northern Ireland said it was challenging to understand whether to follow a UK approach or a devolved approach and often there was mixed messaging between the two administrations which created confusion in the response (P8). A responder from Wales said additional measures had to be put in place before any changes in rules could be enforced leading to further delays in receiving new information. Another responder said this created a "false start" in their response:

[Central Government] constantly fail to say these are the rules for England and everyone just assumes England, Wales and Northern Ireland. Then [...] about two hours after the announcement from central government the Welsh government will add a slight twist, by which time the press have got hold of it and people in Wales will read the paper and think "oh I am allowed to do that" but actually no you're not because the Welsh law is a little bit different [...] it [is] difficult trying to enforce the legislation when we have just read the document so aren't fully up to speed with [...] we are constantly behind the curve (P5).

Yet, it was not just delayed information sharing between a local and national level which made the response challenging, some responders also said conflicting information created challenges. One responder said this caused "confidence and reputational issues" with responders towards the government:

One day we are being told to do one thing and the next day something completely opposite comes out. It makes us question if they really know what they are talking about, why is the change? [...] Consideration as to what comes out and even if it is delayed by a day it can avoid a lot of the contradiction and confusion (P6).

Further exacerbating this disconnect between the national and local level was the inconsistent presence in some areas of a representative from government (Government Liaison Officer [GLO]) in meetings to act as a link between the local responders and central Government. One responder said they were given a different GLO each week and so were unable to form any consistent relationships which presented challenges as there was no dependable channel of communication into central Government, meaning the national and local level groups were working independently of each other (P4). For example, one responder described how national agencies were planning on building a 
testing site at the same location they had locally planned on building a temporary mortuary and this was only uncovered by a chance encounter between a local police officer and members from the national government agency at the site (P16).

However, the inconsistent presence of a GLO was not reported by all responders, with responders from London saying they had a GLO that attended meetings from the beginning. Yet, there was still a clear disconnect between national and local level in this area:

We are not getting information down from government as the government are keeping everything very close to their chest. We have got a number of GLOs in the SCGs that have been involved right from the start, they help with the information flow downwards and they can help facilitate a workaround to ensure that supply chains and what needs to be done can be done to ensure that communication channels can open up again (P3).

3.2.2 Cross-area lesson sharing. In later interviews, whilst communication challenges between national and local levels were still prevalent, some responders reported being less reliant on information coming down from a national level to guide their response, instead taking a more local-level approach. Responders in the South East credited the development of connections with regional partners which facilitated a common regional approach. They said this allowed responders from different areas to compare and discuss what actions were being taken in each region, share relevant information and provide a vital coordination role between regions:

We are now solving the same problem but in a different way [...] we have focussed on regional colleagues and partners, [...] we have agreed a common approach across the South East. We have a workshop on Thursday to compare approaches to the modelling cells, this has enabled us to start comparing (P11).

Further, one responder (P2) in London talked about lesson sharing nationally to enable other areas to learn lessons from London, who in the early months of the pandemic seemed to be worse affected than other areas of the country. In addition, one responder (P17) in Scotland discussed sharing lessons internationally, which came about due to the strong international links they have.

As well as providing practical support, this cross-area connection also provided emotional support through "providing the opportunity to vent and also assurance" (P16). This was also echoed in Scotland where one responder said they recognised that several lives had been lost, and that this was causing an emotional strain for responders:

When London were getting hit about three to four weeks ahead of us, I had a number of one-to-one strategic meeting calls with other strategic commanders in London about how does this feel, not the numbers or sterile meeting room environment but the 'phone a friend' item, how's it going? What does it feel like? (P17).

However, pre-existing relationships with responders from other areas was credited as a key driver behind this cross-area lesson sharing. The responder from Scotland said they depended on their network and relationships that they had built up with others before COVID-19 (P17). Furthermore, a responder from the South East said that there was nothing in guidance about talking to people from other regions:

[Having a regional TCG catch up] came about because we know each other [...] but this structurally is not written down anywhere, [....] speak to your neighbours, speak to your counterparts and actually have a checklist somewhere [...] the things you want to have a think about (P16).

\section{DISCUSSION}

Interviews were conducted with Police, FRS and Ambulance Service responders from across the UK who were involved in the COVID-19 response at a strategic or tactical level. Two key inter-group relations were discussed by responders: (i) horizontal - the relationship between responders at a local level, and (ii) vertical - the relationship between responders at a local and national level. Horizontal intergroup relations were strengthened by pre-existing relationships, understanding the roles of partners, and having a shared understanding of the response. Vertical intergroup relations were challenged by poor communication between national and local level, with this challenge eased in some areas by cross-area lesson sharing.

Key challenges responders faced in the response are discussed below alongside potential solutions and how shared identity might be applied to these multi-agency groups. Discussion is separated by three potential solutions: relationships, common fate, and leadership.

\subsection{Key challenges, potential solutions, and evidence of a shared identity in the multi-agency groups}

4.1.1 Relationships. In earlier interviews, pre-existing relationships were credited by responders as being a key facilitator in initially bringing the multi-agency groups together. For example, responders in London talked about several recent incidents where they had responded together. Based on these recent shared experiences, responders in this area said that relationships with responders from other agencies were already established.

It is well documented within the social identity literature that individuals identifying with members of their group can help the group work more effectively together (Drury et al., 2009; Haslam et al., 2009) and can foster trust in other group members (Turner et al., 1987). In other words, when these relationships are already formed and individuals have had recent shared experiences with each other, it makes it easier for them to act as a group in the present. Based on this, responders in the current study were likely able to benefit from the positive effects of their pre-existing relationships from recent shared experiences immediately.

Despite this, a key challenge several responders highlighted throughout the course of the interviews was that delayed or conflicting communication from a national to local level created difficulties for them in preparing for and providing a timely response. This seemed to be exacerbated in the devolved nations of Northern Ireland and Wales where at times it was unclear whether to follow a national or devolved approach. Yet, in later interviews some responders discussed sharing lessons regionally (South East) nationally (London) and between-nations (Scotland) to try and manage this challenge. Thus, it appears some responders utilised relationships with partners outside of their 
local area as a potential solution to a challenging relationship with national partners. In addition, some responders commented that this cross-area lesson sharing was facilitated by pre-existing relationships with responders from different areas. This suggests that these pre-existing relationships can facilitate group behaviour in the response both early in the response, and in later stages of the response.

4.1.2 Common fate. Several responders used collective terminology when describing the response, particularly in initial interviews when discussing what facilitated group working early on (e.g. "common enemy", "unity", "common purpose"). As such, it seems that the nature of the response also facilitated the group coming together, or in other words it appears the responders experienced a sense of common fate - "a coincidence of outcomes among two or more persons that arises because they have been subjected to the same external forces or decision rules" (Brewer, 2000, p. 118).

Research shows that a sense of common fate between individuals can facilitate a shared identity between members (e.g. Drury, 2018). Subsequently, this shared identity can encourage helpful and empathetic behaviour between group members (e.g. Levine et al., 2005), enhance people's trust with other group members (Cruwys et al., 2020) and increase their willingness to co-operate in working towards group goals (Haslam, 2004). Taken in the context of the current research, a shared sense of purpose in the response to COVID-19 is likely to have facilitated responders coming together psychologically and increased their ability to work collaboratively on the response.

4.1.3 Leadership. An early challenge discussed by responders was the wide range of partners involved in the response who would not typically be involved in an incident response and how pre-existing relationships were not present with these partners. Furthermore, some responders commented how this was exacerbated by the virtual nature of the meetings. Yet, some responders discussed how the Chair of their meetings went over roles and responsibilities at the beginning of the response, or when new partners joined and how this facilitated their ability to work interdependently with, as opposed to independently of each other.

Furthermore, in later interviews when the initial wave of COVID-19 came to an end, some responders said that the initial sense of shared purpose that was present at the beginning of the response had seemed to reduce. As such, some responders said their Chair spent time going over where they were at with the response and outline any outstanding issues to help maintain a common operating picture amongst responders. Thus, according to some responders', their Chair attempted to strategically maintain a shared awareness of the situation in this way, and help facilitate group cohesiveness through ensuring common goals were communicated to all.

According to Zehnder et al. (2017), effective leadership can help organizations foster a sense of shared identity among members - i.e. helping group members see themselves as 'we' as opposed to 'I' (Steffens et al., 2014). Effective leaders can facilitate collaboration between group members (Ellemers et al., 2004), making the group more likely to succeed in their goals (Carton et al., 2014). Recently, Fladerer et al. (2020) showed that leaders were able to reinforce a sense of shared identity amongst group members by using collective language such as "we" as opposed to "I". In turn, this reinforced sense of shared identity within the group was subsequently associated with improved organizational performance, emphasising the importance of effective leadership.

Further, in the context of emergency response, recent research has shown that individual characteristics of the Chair of SCG groups can influence decision-making processes within the group (e.g. Waring et al., 2020; Wilkinson et al., 2019). The research in the current paper expands on this evidence-base through showing that some responders perceived their group leaders to play a particularly important role in facilitating multi-agency working when pre-existing relationships were not already present, or when the sense of common fate began reducing. This echoes further recent research by Fladerer and colleagues who found that identity leadership was particularly relevant in situations where co-workers group identification was low (Fladerer et al., 2021). Thus, this highlights the importance of effective leadership, particularly in new or less wellestablished groups, such as emergency response groups.

\subsection{Strengths and Limitations}

One limitation of the research presented is that only responders from the blue light services were included but the COVID-19 response involved responders from several different organizations. Because of this, it is difficult to discern whether the challenges discussed by responders were common across responders from other organizations. In addition, the varying availability in responders may have biased the results to those who took part in the most interviews. However, several findings from the current research are echoed in the research by Hill et al. (2020; see Hill et al., 2021 for a summary), such as collaborative working being facilitated by pre-existing relationships between partners, yet hindered by partners who had no prior knowledge of the structures or procedures of the SCG and TCG groups. This suggests that the findings of the current research are likely to be both common experiences and generalisable to the wider response partners (see also Radburn et al., 2021).

Of course, it is possible there are factors other than social identity principles that may have impacted multi-agency working in the COVID-19 response. For example, responders from the South East said they introduced a period of stabilisation in between the usual 'Response' and 'Recovery' phase - an interim control stage to mitigate the risk of secondary impacts occurring, as well as allowing multi-agency coordination groups to retain their overall focus on reducing the risk of the current threat (Deeming $\&$ Burgess, 2017; cf. Deeming, 2020). Recent research looking at multi-agency response to a simulated terrorist incident also found benefits of a three-phased approach (Brown et al., 2021). Brown and colleagues suggest that an additional phase in between response and recovery can increase opportunities for collaborative working across agencies and reduce demands on a single team. As such, it should not be ignored that factors other than social identity principles can also facilitate effective multi-agency response.

Finally, to our knowledge, this is the first research that applies social identity principles to better understand multi-agency working in emergency response. This research clearly demonstrates that group relations played an important role in the multi-agency response to COVID-19. However, future research would benefit from further investigating this to allow for concrete practical recommendations to be drawn.

\subsection{Conclusion}

The evidence from interviews with strategic and tactical responders involved in the COVID-19 response show that intergroup relations played an important role in group working during the multi-agency response, both at the horizontal and vertical level. Responders discussed different factors that impacted group working during the COVID-19 
response. Group working was facilitated within the multi-agency groups from prior relationships with other responders and in turn this facilitated the ease at which responders were able to come together initially and work together in the response. Further, a shared sense of common fate against COVID-19 also appeared to facilitate group working during the initial months of the pandemic. However, when pre-existing relationships were not present, or when the initial threat of COVID-19 started reducing, Chairs of the multi-agency groups spent time going over roles and responsibilities of partners, or by going over the shared goals of the response which in turn may have worked to strategically facilitate group working.

\subsection{Practitioner points}

- Relationships between responders from different organizations should be nurtured to ensure that a shared identity is maintained between responders to facilitate the ease at which they are able to come together for future incident responses.

- When responders share difficult or challenging experiences with each other, this can help them feel connected to each other, regardless of their organization, and responders should be encouraged to use collective terminology, such as 'we' and 'us' to facilitate this.

- Leadership is important in facilitating a shared identity and Chairs of the multi-agency groups can help strategically embed a shared identity if relationships are not already present or if there is not a strong sense of common fate between responders through specific actions such making roles and responsibilities of partners clear and reiterating shared goals.

\section{References}

- Bang, D., \& Frith, C. D. (2017). Making better decisions in groups. Royal Society Open Science, 4(8), 170193. doi: 10.1098/rsos.170193

- Braun, V., \& Clarke, V. (2006). Using thematic analysis in psychology. Qualitative Research in Psychology, 3(2), 77-101. doi: 10.1191/1478088706qp063oa

- Brewer, M. B. (2000). Superordinate goals versus superordinate identity as bases of intergroup cooperation. In D. Capozzo \& R. Brown (Eds.), Social identity processes: Trends in theory and research (pp. 117-132). London: Sage.

- Britton, P. (2021, May 18). Manchester Arena Inquiry LIVE as former GMP chief says major incident was declared 'far too late'. Manchester Evening News. Retrieved from: https://www.manchestereveningnews.co.uk/news/greater-manchester-news/manchester-arena-inquiry-live-former-20619969

- Brown, O., Power, N., \& Conchie, S. M. (2021). Communication and coordination across event phases: A multi-team system emergency response. Journal of Occupational and Organizational Psychology. doi: 10.1111/joop.12349

- Cabinet Office (2013a). Lexicon of UK Civil Protection Terminology. Retrieved from https://www.gov.uk/government/publications/emergency-responder-interoperabilitylexicon

- Cabinet Office. (2013b). Emergency Response and Recovery: Non-Statutory Guidance Accompanying the Civil Contingencies act 2004. Retrieved from: https://www.gov.uk/guidance/emergency-response-and-recovery\#principles-of-effective-response-and-recovery

- Carton, A. M., Murphy, C., \& Clarke, J. R. (2014). A (blurry) vision of the future: How leader rhetoric about ultimate goals influence performance. Academy of Management Journal, 57(6), 1544-1570. doi: 10.5465/amj.2012.0101

- Civil Contingencies Act. (2004). Civil Contingencies Act. Retrieved from: https://www.legislation.gov.uk/ukpga/2004/36/contents

- Cruwys, T., Stevens, M., Platow, M. J., Drury, J., Williams, E., Kelly, A. J., \& Weekes, M. (2020). Risk-taking that signals trust increases social identification. Social Psychology, 51(5), 319-399. doi: 10.1027/1864-9335/a000417

- Deeming, H., \& Burgess, J. (2017). Stabilisation: a discussion of the concept's relevance to UK Resilience. HD Research. Retrieved from https://drive.google.com/file/d/1ch152MBFfmMPsWj2uowgpD4ddvUEmVME/view

- Deeming, H. (2020). Briefing note: 'The stabilisation phase' as the correct descriptor for the transition between response to and from recovery from Covid-19. HD Research. Retrieved from: https://www.researchgate.net/publication/340923284_HDR-Stabilisation_Briefing_note_Final_short

- Drury, J., Cocking, C., \& Reicher, S. (2009). The nature of collective resilience: survivor reactions to the 2005 London bombings. International Journal of Mass Emergencies and Disasters, 27(1), 66 - 95

- Drury, J. (2018). The role of social identity processes in mass emergency behaviour: An integrative review. European Review of Social Psychology, 29(1), 38-81. doi: $10.1080 / 10463283.2018 .1471948$

- Ellemers, N., De Gilder, D., \& Haslam, S. A. (2004). Motivating individuals and groups at work: A social identity perspective on leadership and group performance. The Academy of Management Review, 29(3), 459. doi: 10.2307/20159054

- Fladerer, M. P., Haslam, S. A., Steffens, N. K., \& Frey, D. (2020). The value of speaking for "us": The relationship between CEO's use of I- and we-referencing language and subsequent organizational performance. Journal of Business and Psychology, 36(2), 299-313. doi: 10.1007/s10869-019-09677-0

- Fladerer, M. P., Kugler, S., \& Kunze, L. G. (2021). An exploration of co-workers' group identification as moderator of the leadership-health link. Small Group Research. doi: $10.1177 / 10464964211007562$

- Haslam, S. A., Postmes, T., \& Ellemers, N. (2003). More than a metaphor: Organizational identity makes organizational life possible. British Journal of Management, 14, 357369. doi: 10.1111/j.1467-8551.2003.00384.x

- Haslam, S. A. (2004). Psychology in organizations: The social identity approach. Sage

- Haslam, S. A., Jetten, J., \& Waghorn, C. (2009). Social identification, stress and citizenship in teams: a five-phase longitudinal study.Stress and Health, 25(1): 21-30

- Haslam, S. A., Reicher, S. D., \& Levine, M. (2012). When other people are heaven, when other people are hell: How social identity determines the nature and impact of social support. In J. Jetten, C. Haslam \& S.A. Haslam (Eds.), The social cure: Identity, health and well-being (pp. 157-174). London: Psychology Press

- Haslam, S. A., Haslam, C., Cruwys, T., Jetten, J., Bentley, S. V., Fong, P., \& Steffens, N. K. (2021). Social identity makes group-based social connection possible: implications for loneliness and mental health. Manuscript submitted for publication.

- Hill, R., Guest, D., Hopkinson, A., Towler, A., \& Pickford, R. (2020a). Covid-19 Pandemic National Interim Operational Review: C19 National Foresight Group. Retrieved from: https://www.ntu.ac.uk/_data/assets/pdf file/0028/1177912/NTU-C19-NFG-Report-300620-First-Interim-Operational-Review-Report.pdf

- Hill, R., Guest, D., Pickford, R., Hopkinson, A., Daszkiewicz, T., Whitton, S., Reed, I., \& Towler, A. (2020b). Covid-19 Pandemic Second Interim Operational Review: C19 National Foresight Group. Retrieved from: https://www.ntu.ac.uk/_data/assets/pdf_file/0030/1177905/NTU-C19-NFG-Report-110520-Second-Interim-Operational-Review- 


\section{Report.pdf}

- Hill, R., Guest, D., Pickford, R., Hopkinson, A., Daszkiewicz, T., Whitton, S., Reed, I., Thomas, I., \& Crego, J. (2020). Covid-19 Pandemic Third Interim Operational Review: C19 National Foresight Group. Retrieved from: https://www.ntu.ac.uk/_data/assets/pdf_file/0033/1196745/NTU-C19-NFG-Report-261020-Third-Interim-Operational-ReviewReport.pdf

- Joint Emergency Services Interoperability Principles [JESIP]. (2013). Joint Doctrine: The Interoperability Framework. Retrieved from: https://www.ukfrs.com/sites/default/files/2017-09/JESIP\%20Joint\%20Doctrine\%20-\%20The\%20Interoperability\%20Framework.pdf

- Joint Emergency Services Interoperability Principles [JESIP]. (2016). Joint Doctrine: The Interoperability Framework, Edition 2. Retrieved from: https://www.jesip.org.uk/uploads/resources/JESIP-Joint-Doctrine.pdf

- Joint Emergency Services Interoperability Principles [JESIP]. (2021). Joint Doctrine: The Interoperability Framework, Edition 3. Retrieved from: https://www.jesip.org.uk/jointdoctrine

- Kerslake. (2018). The Kerslake Report: An Independent Review into the Preparedness for, and Emergency Response to the Manchester Arena Attach on 22 nd May 2017. Retrieved from: https://www.jesip.org.uk/uploads/media/Documents\%20Products/Kerslake_Report_Manchester_Are.pdf

- Levine, M., Prosser, A., Evans, D., \& Reicher, S. (2005). Identity and emergency intervention: how social group membership and inclusiveness of group boundaries shape helping behaviour. Personality and Social Psychology Bulletin, 31(4), 443-453. doi: 10.1177/0146167204271651

- Mathieu, J. E., Marks, M. A., \& Zaccaro, S. J. (2001). Multiteam systems. In N. Anderson, D. S. Ones, H. K. Sinangil \& C. Viswesvaran (Eds.), Handbook of industrial, work and organizational psychology (pp. 289-313). London, UK: Sage Publications.

- Millward, L. J., \& Haslam, S. A. (2013). Who are we made to think we are? Contextual variation in organizational, workgroup and career foci of identification. Journal of Occupational and Organizational Psychology, 86, 50-66. doi: 10.1111/j.2044-8325.2012.02065.x

- Pollock, K. (2013). Review of Persistent Lessons Identified Relating to Interoperability from Emergencies and Major Incidents Since 1986. Retrieved from http://www.jesip.org.uk/wp-content/uploads/2013/07/Pollock-Review-Oct-2013.pdf

- Pollock, K. (2017). Local Interoperability in UK Emergency Management: A Research Report. Retrieved from https://www.researchgate.net/publication/336719370_Local_Interoperability_in_UK_Emergency_Management_A_Research_Report_Commissioned_by_the_Cabinet_Office_and_

- Pollock, K. (2021). Lessons Will Be Learned" A euphemism for failure?". Retrieved from https://www.researchgate.net/publication/348235663_Lessons_Will_Be_Learned_A_euphemism_for_failure

- Power, N., \& Alison, L. (2018). Decision inertia in critical incidents. European Psychologist, 24(3), 209-218. doi: 10.1027/1016-9040/a000320

- Power, N., \& Alison, L. (2017). Redundant deliberation about negative consequences: Decision inertia in emergency responders. Psychology, Public Policy, and Law, 23(2), 243-258. doi: 10.1037/law0000114.

- Radburn, M., Stott, C., Bryant, R., Morgan, B., Tallent, D., \& Davidson, L. (2021). Group processes and interoperability: a longitudinal case study analysis of the UK's civil contingency response to Covid-19. Manuscript submitted for publication

- Reicher, S., Spears, R., \& Haslam, S. A. (2010). The Social Identity Approach in Social Psychology. In Wetherell, M. S. \& Mohanty, C. T. (eds),Social Identities Handbook. London: Sage

- Steffens, N. K., Haslam, S. A., Reicher, S. D., Platow, M. J., Fransen, K., Yang, J., ... \& Boen, F. (2014). Leadership as social identity management: Introducing the identity leadership inventory (ILI) to assess and validate a four-dimensional model. The Leadership Quarterly, 25(50), 1001-1024. doi: 10.1016/j.leaqua.2014.05.002

- Tajfel, H., \& Turner, J. (1979). An integrative theory of intergroup conflict. In W. G. Austin \& S. Worchel (Eds.),The social psychology of intergroup relations. Monterey, CA: Wadsworth

- Turner, J, C. (1982). Towards a cognitive redefinition of the social group. In H, Tajfel (Eds), Social identity and intergroup relations. Cambridge University Press, Cambridge

- Turner, J. C. (1985). Social categorization and the self-concept: A social cognitive theory of group behaviour. In E. J. Lawler (Eds.), Advances in group processes, Greenwich, CT.

- Turner, J. C., Hogg, M. A., Oakes, P. J., Reicher, S. D., \& Wetherell, M. S. (1987). Rediscovering the social group: a self-categorization theory. Oxford, UK: Blackwell

- Waring, S., Alison, L., Carter, G., Barrett-Pink, C., Humann, M., Swan, L., \& Zilinsky, T. (2018). Information sharing in interteam responses to disaster. Journal of Occupational and Organizational Psychology, 91(3), 591-619. doi: 10.1111/joop.12217

- Waring, S., Moran, J., \& Page, R. (2020). Decision-making in multiagency multiteam systems operating in extreme environments. Journal of Occupational and Organizational Psychology, 93(3), 629-653, doi: 10.1111/joop.12309

- Wilkinson, B., Cohen-Hatton, S. R., \& Honey, R. C. (2019). Decision-making in multi-agency groups at simulated major incident emergencies: In situ analysis of adherence to UK doctrine. Journal of Contingencies and Crisis Management, 27(4), 306-316. doi: 10.1111/1468-5973.12260

- Wilkinson, B., Cohen-Hatton, S. R., \& Honey, R. C. (2021). Variation in exploration and exploitation in group decision-making: Evidence from immersive simulations of major incident emergencies. Journal of Contingencies and Crisis Management. doi: 10.1111/1468-5973.12355

- Zehnder, C., Herz, H., \& Bonardi, J. P. (2017). A productive clash of cultures: injecting economics into leadership research. The Leadership Quarterly, 28(1), 65-85. doi: 10.1016/j.leaqua.2016.10.004 
